RAPID EXTRACTION OF COPPER (II) WITH 1-PHENYL-3-METHYL-4-
NITROBENZOYL- 5-PYRAZOLONE IN DIFFERENT ORGANIC DILUENTS

M.O.C. OGWUEGBU,

School of Physical Sciences, Abia State University, P.M.B. 2000, Uturu, Nigeria

AND

N.C. OFORKA and A.I. SPIFF

Department of Pure and Industrial Chemistry, University of Port Harcourt, Port Harcourt, Nigeria.
(Date of receipt : 23 November 1990)
(Date of acceptance : 25 June1992)

\begin{abstract}
Solvent extraction of Copper (II) using 1-Pheny1-3-methyl-4-nitrobenzoyl-5pyrazolone (HNPZ) in various organic solvents has been studied. The extractable species has been identified by investigation of $\log -\log$ plot of distribution ratios and reagent concentrations. Job's method and mole ratio method confirmed the mole ratio Cu:HNPZ to be 1:2. Maximum and reproducible results were obtained at pH 4-6, and equilibration was achieved within few seconds. We also observed that the capacity of the organic loading was significantly higher when chloroform and benzene were used as solvents. Equilibrium extraction constant, $\log K_{\text {ex }}$, was determined from experimental data as -1.60 .
\end{abstract}

\title{
INTRODUCTION
}

$\beta$ - diketones have been extensively and successfully employed as chelating agents in the extraction of metals. But of these, thenoyltrifluoroacetone (TTA) ${ }^{1}$, acetylacetone (AA) and trifluoroacetyl-acetone (TFA) ${ }^{2,3}$ are more widely used.

Recently, however, acyl pyrazolones and 4-benzoyl-3-methyl-1-phenyl-5-pyrazolone $(\mathrm{BMPP})^{4}$ have been introduced. Much of the recent work reported in the literature has been done with BMPP rather than its derivatives. In this paper, the results of our study of solvent extraction of $\mathrm{Cu}$ (II) with the nitro-derivative, 1-phenyl-3-methyl-4nitrobenzoyl-5-pyrazolone is presented. Rao et al. ${ }^{5}$ have previously used this for the extraction of $\mathrm{U}(\mathrm{VI})$. The presence of a nitro group in the ligand is expected to enhance the acidic properties of the reagent and hence its extractive property. Since the pKa values of BMPP and HNP are comparable, $\mathrm{HNP}_{\mathrm{Z}}$ is expected to be equally good in solvent extraction. The liquid-liquid extraction behaviour of copper (II) with the ligand, and the dependency of the extraction processes on $\mathrm{pH}$, ligand concentration and contact time are reported here. 


\section{METHOBS AND MATERIALS}

\section{Apparatus and Reagents}

The intermediate compound, 3-methyl-1-phenyl-5-pyrazolone (MPP) was synthesized from analytical grade ethylacetoacetate and phenylhydrazine. $\mathrm{HNP}_{\mathrm{Z}}$ was prepared subsequently from MPP and high grade p-nitrobenzoylchloride (BDH) and purified as described elsewhere for the acyl pyrazolones. Stock solutions of $\mathrm{Cu}$ (II) were prepared by dissolving $0.098 \mathrm{~g}$ of analytical grade $\mathrm{CuSO}_{4} .5 \mathrm{H}_{2} \mathrm{O}$ in $250 \mathrm{ml} 0.1 \mathrm{M} \mathrm{HCl}$ or $0.1 \mathrm{M} \mathrm{HNO}_{3}$ solution. Further dilutions were made as required. Solutions of $0.02 \mathrm{M} \mathrm{HNP} Z$ were prepared in different organic solvents, and further dilutions were made as required. Standard buffer solutions of $\mathrm{HCI} / \mathrm{KCI}, \mathrm{HAc} / \mathrm{NaAc}$ and $\mathrm{NaOH} /$ boric acid were used in the $\mathrm{pH}$ range 1 - 8. Apart from the $\mathrm{pH}$ variation studies, all experiments were conducted at $\mathrm{pH}$ 4.0. In carrying out the studies, the aqueous phase was prepared in each case to maintain constant ionic strength of 0.10 using sodium sulphate $\left(\mathrm{Na}_{2} \mathrm{SO}_{4} \cdot 10 \mathrm{H}_{2} 0\right)$ solution. The ionic strength is considered to have negligible effect on the extraction equilibrium constant, $\mathrm{K}_{\mathrm{ex}}$ in the $\mathrm{pH}$ range and total ionic concentrations studied.

The ligand has been characterized by elemental analysis, IR, UV-Visible and melting point measurements. The cream coloured pure product was found to have a melting point of $164 \pm 0.5^{\circ} \mathrm{C}$.

PYE Unicam SP6-400 and Shimadzu-408 IR Spectrophotometers were used for spectrophotometric measurements. In all cases, the initial and equilibrium $\mathrm{pH}$ were recorded using a $\mathrm{pH}$ meter standardized with a buffer solution of $\mathrm{pH} 4.0$.

\section{Extraction Procedure}

$5 \mathrm{ml}$ aliquot of $\mathrm{Cu}(\mathrm{II})$ solution $(50 \mathrm{ppm})$ and similar volume of $0.02 \mathrm{MHNP}_{\mathrm{Z}}$ solution in chloroform, benzene, toluene or ethylacetate were mixed and agitated by means of a mechanical stirrer for 10 mins. However, equilibration was achieved within a few seconds. After allowing for the separation of the two phases, the amount of copper remaining in the aqueous phase was determined spectrophotometrically at $440 \mathrm{~nm}$ using benzoin-a-oxime. ${ }^{7}$ The concentration of copper extracted into the organic phase was obtained by material balance. The distribution ratio, $D$, of copper was determined as the total concentration of it in the organic phase divided by the total concentration in the aqueous phase of two mutually equilibrated sensibly immiscible liquid phases.

\section{RESULTS AND DISCUSSION}

\section{Absorption Curves}

In order to determine the molar absorptivities and wavelengths of maximum absorption for $\mathrm{HNP}_{\mathrm{Z}}$ and $\mathrm{Cu}$ (II)-nitrophyrazolonate complex, the latter was isolated in its solid from mixing $0.808 \mathrm{~g}(0.0025 \mathrm{~mol})$ of $\mathrm{CuSO}_{4} .5 \mathrm{H}_{2} \mathrm{O}$ in $50 \mathrm{ml}$ of distilled water and $1.6166 \mathrm{~g}$ 
$(0.005 \mathrm{~mol})$ of $\mathrm{HNP}_{\mathrm{z}}$ in $50 \mathrm{ml}$ of ethanol. The appearance of yellow-green precipitate was instantaneous. Figure 1 shows the absorption spectra of $\mathrm{HNP}_{\mathrm{Z}}$ and $\mathrm{Cu}(\mathrm{II})$ complexes. The appearance of maximum absorption at similar wave lengths ruled out the possibility of spectrophotometric studies of the equilibrated organic phase for copper concentrations. Hence the extraction studies were spectrophotometrically done in the aqueous phase. The molar absorptivities for the ligand and copper complex at $360 \mathrm{~nm}$ and $370 \mathrm{~nm}$ were $5.4 \times 10^{2}$ and $3.3 \times 10^{3} 1 \mathrm{~mol}^{-1} \mathrm{~cm}^{-1}$ respectively.

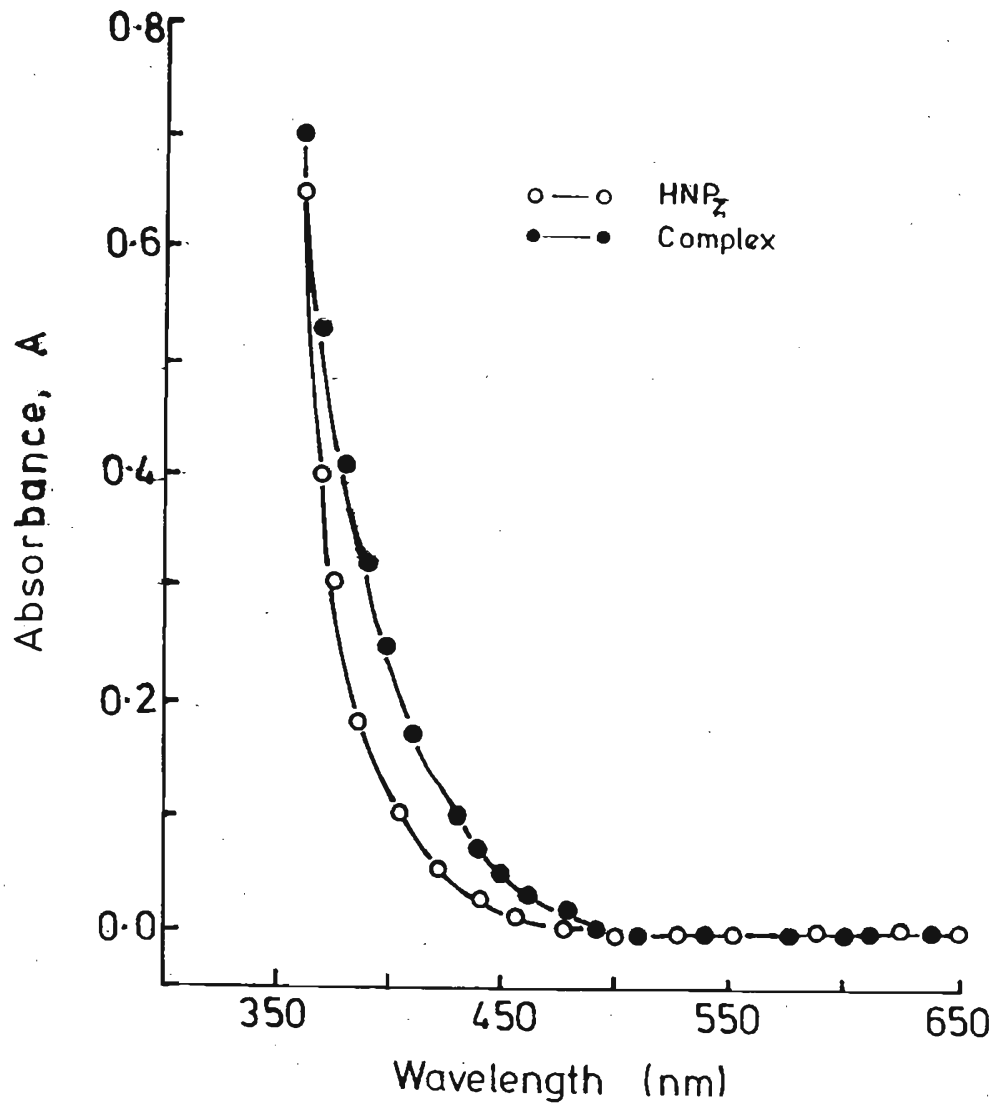

Figure 1: Absorption spectra of HNPZ and complex.

\section{Effect of pH}

The results are given in Figure 3. Experiments conducted to study the effect of variation of $\mathrm{pH}$ on the extraction of copper at constant excess ligand concentration, $\mathrm{HNP}_{\mathrm{Z}}=$ $0.02 \mathrm{M}$, indicates that between $\mathrm{pH} 4.0$ and 6.0 , copper is completely extracted and the slope of the linear portion of the plot of $\log \mathrm{D}$ vs $\mathrm{pH}$ is approximately two, indicating that two moles of protons are liberated during complex formation. The result shows that the extraction of copper using this reagent is hydrogen ion concentration dependent 
up to $\mathrm{pH}$ of 4.0 , and followed by a non-dependent horizontal region. Within this buffer region the slope is equal to zero up to $\mathrm{pH}$ of 6.0 when the extraction process seems to have reversed as the aqueous phase becomes more basic.

Preliminary investigation on the effect of complexing agents on the extraction of $\mathrm{Cu}$ (II) showed that at the concentrations used in preparing the aqueous buffer media, the components of the buffer solutions had no effect on the general extraction processes. But in the presence of diverse ions, $\mathrm{Cu}$ (II) is found to be quantitatively extracted with $\mathrm{Fe}$ (III) between pH 3.0 to 4.0. However, $\mathrm{Fe}$ (III) is completely masked by EDTA $\left(<10^{-3} \mathrm{M}\right)$ and oxalate ions $\left(<10^{-2} \mathrm{M}\right)$, while at the same masking-agent concentrations, more than $99 \%$ of $\mathrm{Cu}(\mathrm{II})$ is extracted when oxalate ions are used as masking agents. Nickel (II) is negligibly extracted with chloroform solution of $\mathrm{HNP}_{\mathrm{Z}}$ at the $\mathrm{pH}$ and equilibration time used for this study, while Co (II) is only extracted from $\mathrm{pH} 6.0$ aqueous solutions. With proper choice of extraction chemical parameters, $\mathrm{HNP}_{\mathrm{Z}}$ could be a good selective reagent for copper.

\section{Effect of Ligand Concentration}

Figure 2 shows the log-log plot of distribution ratio, D and ligand concentration at constant $\mathrm{pH}$ 4.0. A straight line for the copper complex is obtained with slope $=2.0$, showing that the number of ligand molecules entering into the extracted complex is two. The plot also shows that at lower ligand concentrations, $\mathrm{Cu}: \mathrm{HNP}_{\mathrm{Z}}$ mole ratio of 1:1 is formed. That means that at lower ligand concentrations up to $0.0016 \mathrm{M}$, copper forms a 1:1 complex with the reagent, while at higher ligand concentrations up to $0.0125 \mathrm{M}$, a 1:2 complex is formed, from which point further increase in ligand concentration produced no more effect in the degree of extraction (Table 1). Since the slopes of Figures. 2 and 3 are two and it has been accepted that two moles of the ligand are used up with subsequent release of two moles of $\mathrm{H}^{+}$ions in the formation of extractable complex, it can therefore be reasonably assumed that the extraction process for copper follows the following extraction equilibrium equation.

$$
\mathrm{Cu}_{(\mathrm{aq})}^{2+}+2 H N P_{\mathrm{Z}(\mathrm{org})} \stackrel{K_{\mathrm{ex}}}{\rightleftharpoons} \mathrm{Cu}\left(N P_{\mathrm{Z}}\right)_{2(\mathrm{org})}+2 H_{(\mathrm{aq})}^{+}
$$

with the equilibrium extraction constant, $\mathrm{K}_{\mathrm{ex}}$ given by:

$$
K_{\mathrm{ex}}=\left[C u\left(N P_{\mathrm{Z}}\right)_{2}\right]_{(\mathrm{org})}\left[H^{+}\right]_{(\mathrm{aq})}^{2}\left[\mathrm{Cu}^{2+}\right]_{(\mathrm{aq})}^{-1}\left[H N P_{\mathrm{Z}}\right]_{(\mathrm{org})}^{-2}
$$

Since the ratio of $\left[\mathrm{Cu}\left(\mathrm{NP}_{\mathrm{Z}}\right)_{2}\right]_{(\text {org })}$ to $\left[\mathrm{Cu}^{2+}\right]_{(\mathrm{aq})}$ is the distribution ratio, D, we then have:

and

$$
D=K_{\mathrm{ex}}\left[H N P_{\mathrm{Z}}\right]_{(\mathrm{org})}^{2}\left[H^{+}\right]_{(\mathrm{aq})}^{-2}
$$

$$
\log D=\log K_{\mathrm{ex}}+2 \log \left\{H N P_{\mathrm{Z}}\right\}_{(\mathrm{org})}+2 p H
$$




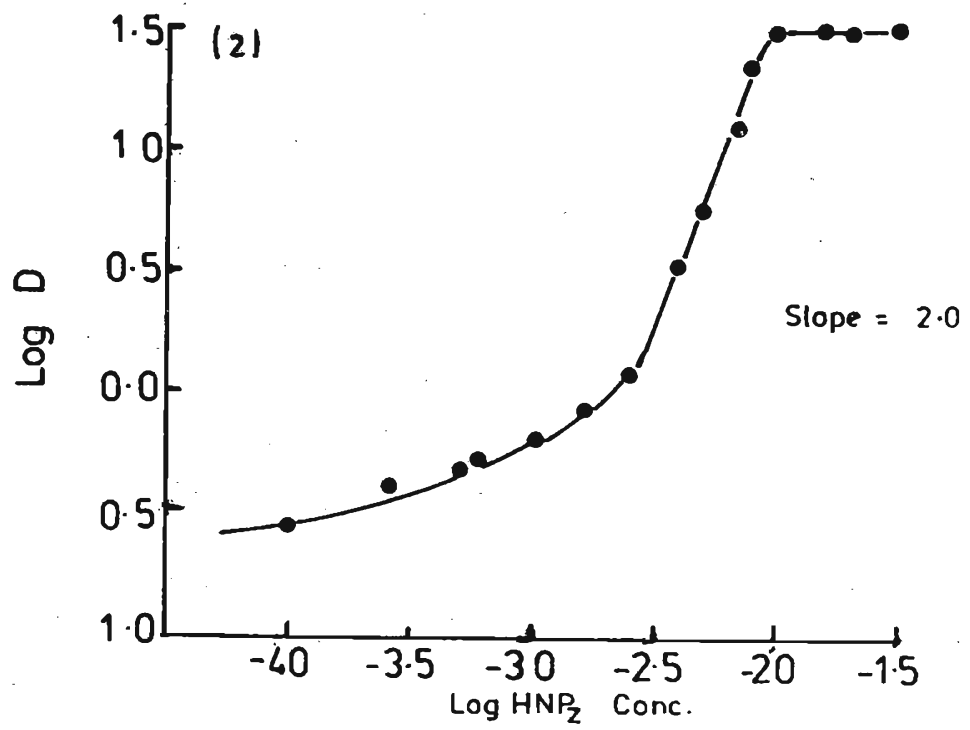

Flgure 2: Exiraction as a function of ligand concentration; $\mathrm{pH}=4.0,[\mathrm{Cu}(\mathrm{II})]=1.57 \times 10^{-4} \mathrm{M}$.

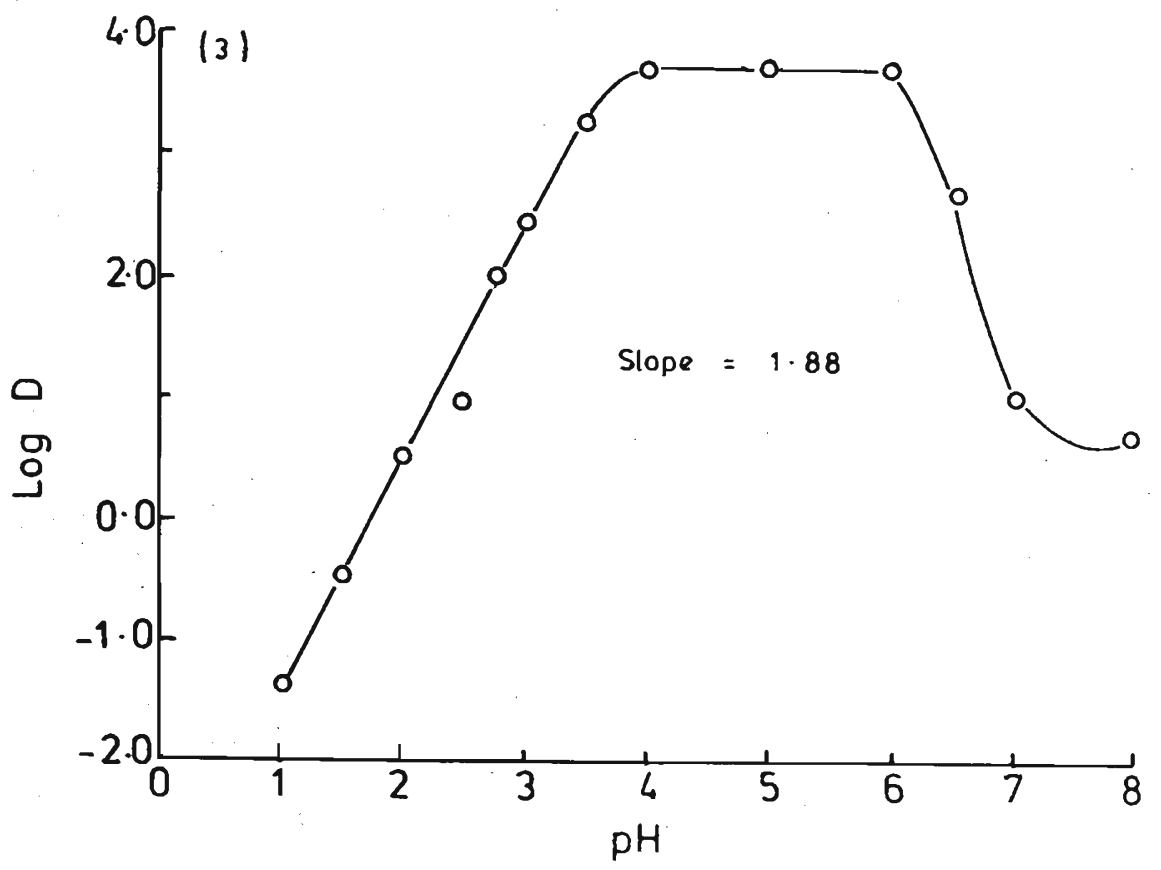

Figure 3: Extraction as a function of $\mathrm{pH} ;[\mathrm{HNPZ}]=0.02 \mathrm{M} ;[\mathrm{Cu}(\mathrm{II})]=1.57 \times 10^{-4} \mathrm{M}$. 
The $\log \mathrm{K}_{\mathrm{ex}}$ found using the above relationship is - 1.60: It has been known that log $K_{\text {ex }}$ increases with decrease in $\mathrm{pKa}$ value of ligand in the extraction of a number of metals. The introduction of a nitro group is expected to enhance the acid properties of the reagent, decrease the $\mathrm{pKa}$ value of BMPP from 4.11, and increase the $\mathrm{K}_{\mathrm{ex}}$ for copper. The value of -1.60 obtained in this experiment and the inconsistent results of other researchers for BMPP point to some unidentified inherent chemical and structural factors that tend to dominate the proton release during the extraction process, such as steric hindrance, oxidation characteristics of the ligand, mesomeric effects, etc. These factors may perhaps tend to increase the $\mathrm{pKa}$ value of the nitropyrazolone, and therefore, decrease the $\mathrm{K}_{\mathrm{ex}}$ for the pyrazolonate complex. Mirza ${ }^{8}$ has found $\log \mathrm{K}_{\mathrm{ex}}$ for extraction of $\mathrm{Cu}$ (II) using BMPP as -0.77 , and Arora ${ }^{9} 0.70$ and Zolotov ${ }^{10} 1.36$. The value of -1.40 has also been reported for $\mathrm{Cu}$ (II) using TTA ${ }^{8}$. Experimental data show that $0.0125 \mathrm{M}$ $\mathrm{HNP}_{\mathrm{Z}}$ is sufficient for $100 \%$ extraction of copper when all other factors are kept constant.

\section{The Composition of the Complex}

Essentially, the determination of the formula of a complex involves the measurement of the number of ligands complexing with one mole of metal ion. Investigation of composition of extractable copper nitropyrazolonate were carried out using Job's method and the mole ratio method at $\mathrm{pH} 4.0$. The results obtained are given in Figures 4 and 5 respectively. In the Job's method, equimolar solutions of the metal salt and $\mathrm{HNP}_{\mathrm{Z}}$ were prepared such that $C_{\mathrm{Cu}}=C_{\mathrm{HNP}_{\mathrm{Z}}}=1.6 \times 10^{-3} \mathrm{M}$ and $C_{\mathrm{Cu}}=C_{\mathrm{HNP}_{\mathrm{Z}}}=8.0 \times 10^{-4} M$.

Their concentrations were varied by varying their volumes from $1 \mathrm{ml}$ to $10 \mathrm{ml}$ and mixed in such a way that the total volume of each mixture is the same $(10 \mathrm{ml})$. The concentrations of copper in the organic phase were plotted against the molar fractions (deduced from volume fractions) of $\mathrm{Cu}$ (II) in the aqueous phase as shown in figure 5. The maximum concentration of $\mathrm{Cu}$ (II) species in the organic phase appears at the molar fraction of $\mathrm{Cu}(\mathrm{II})$ of 0.33 . In Figure 4, the results obtained in the extraction of copper with various amounts of $\mathrm{HNP}_{\mathrm{Z}}$ gave straight lines with points of intersection at the mole ratio of $\mathrm{HNP}_{\mathrm{Z}}$ to $\mathrm{Cu}$ (II) of 2.0. It is obvious from these data that the concentration of copper in the organic phase is maximum for those mixtures in which the molar ratios (or volumes of the equi-molar solutions) of $\mathrm{Cu}$ (II) and $\mathrm{HNP}_{\mathrm{Z}}$ are in the ratio 1:2. The results obtained from Figures 2 to 5 show that extractable species is present as a bis (nitropyrazolonato) copper (II), $\mathrm{Cu}\left(\mathrm{NP}_{\mathrm{Z}}\right)_{2}$ complex. 


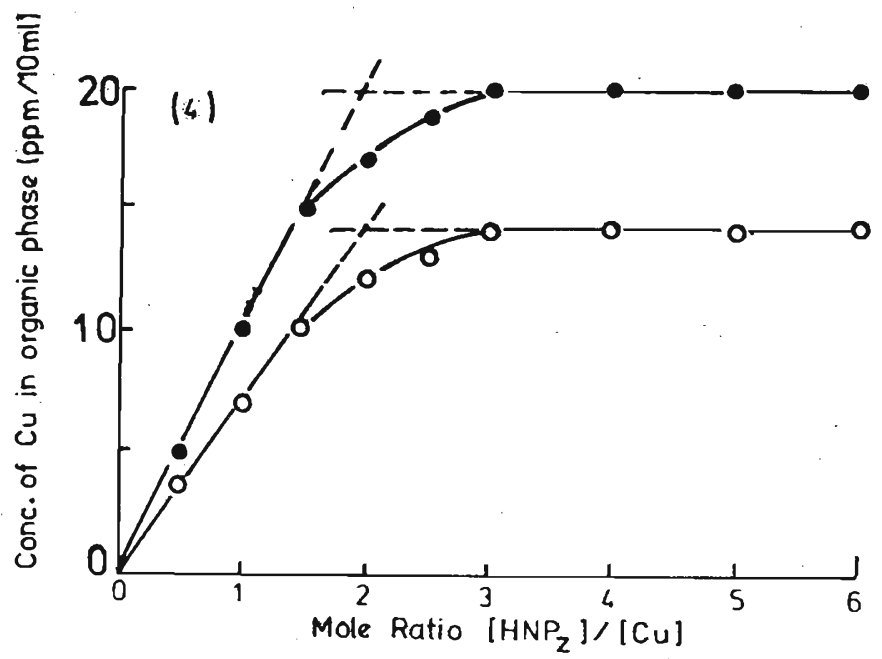

Figure 4: Deternination of composition by mole ratio method.

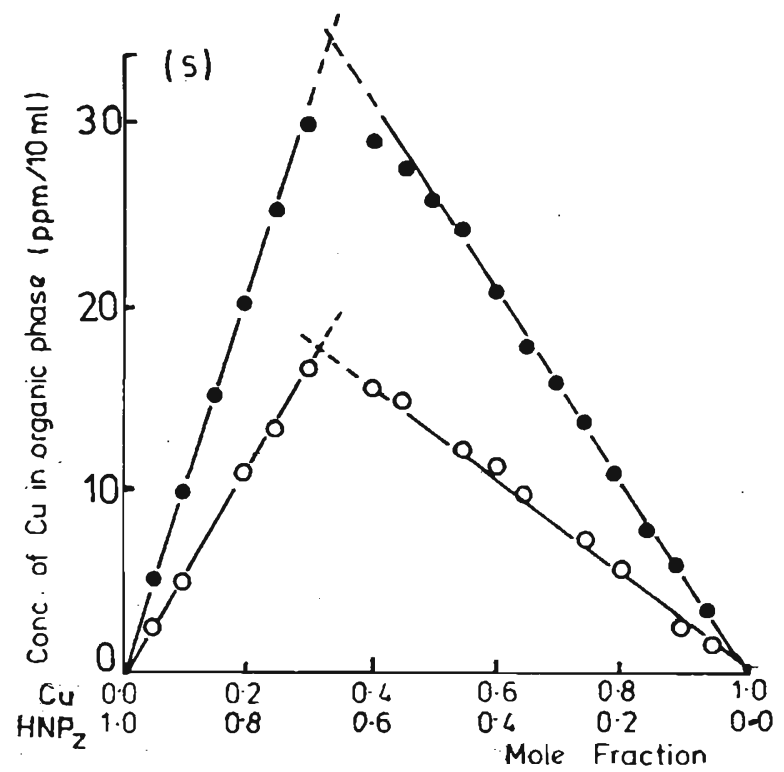

Figure 5: Determination of composition by Job's method. 
Table 1: Effect of Ligand Concentration on Cu(II) extraction

\begin{tabular}{|c|c|c|c|c|c|c|c|}
\hline $\begin{array}{l}\text { Conc } \\
10^{3} \times H N P_{z}\end{array}$ & $\begin{array}{c}\text { Absorbance } \\
\text { A }\end{array}$ & $\begin{array}{l}\text { Log } \\
\text { HNPZ }\end{array}$ & $\begin{array}{l}\text { Conc. of } \\
\mathrm{Cu}(\mathrm{II}) \mathrm{in} \\
\text { Aq. (ppm) }\end{array}$ & $\begin{array}{l}\text { Conc .of } \\
\mathrm{Cu} \text { (II) in } \\
\text { org. (ppm) }\end{array}$ & D & $\log D$ & $\% \mathrm{E}$ \\
\hline 0.0756 & 0.449 & 4.12 & 46.50 & 3.50 & 0.076 & -1.20 & 7.00 \\
\hline 0.10 & 0.391 & -4.00 & 40.50 & 9.50 & 0.235 & -0.630 & 19.00 \\
\hline 0.25 & 0.336 & -3.60 & 36.00 & 14.00 & 0.389 & -0.410 & 28.00 \\
\hline 0.50 & 0.330 & -3.30 & 34.50 & 15.50 & 0.450 & -0.347 & 31.00 \\
\hline 0.75 & 0.325 & -3.12 & 34.00 & 16.00 & 0.470 & -0.327 & 32.00 \\
\hline 1.00 & 0.292 & -3.00 & 30.60 & 19.40 & 0.624 & -0.200 & 38.00 \\
\hline 1.60 & 0.265 & -2.80 & 27.80 & 22.20 & 0.800 & -0.098 & 44.00 \\
\hline 2.50 & 0.193 & 2.60 & 20.00 & 30.00 & 1.500 & -0.176 & 60.00 \\
\hline 4.00 & 0.110 & -2.40 & 12.00 & 38.00 & 3.167 & .0 .500 & 76.00 \\
\hline 5.00 & 0.069 & -2.30 & 8.00 & 42.00 & 5.250 & -0.720 & 84.00 \\
\hline 7.00 & 0.031 & -2.16 & 3.50 & 46.50 & 13.286 & -1.123 & 93.00 \\
\hline 8.00 & 0.014 & -2.10 & 2.00 & 48.00 & 24.000 & -1.380 & 96.00 \\
\hline 10.00 & 0.005 & -2.00 & 0.05 & 49.50 & 0.900 & 3.00 & 99.00 \\
\hline 20.00 & 0.000 & -1.70 & 0.00 & 50.00 & 0.990 & 3.00 & 100 \\
\hline
\end{tabular}

\section{Effects of Solvents}

Data on the effect of various organic diluents on $\mathrm{Cu}(\mathrm{II})$ extraction are shown Figure 6. Maximum extraction is achieved using chloroform and benzene. Wider $\mathrm{pH}$ range within which copper can be extracted using our reagent is possible with chloroform and reverse is the case with benzene. $\mathrm{HNP}_{\mathrm{Z}}$ and $\mathrm{Cu}\left(\mathrm{NP}_{\mathrm{Z}}\right)_{2}$ are found to have limited solubility in carbon tetrachloride, ethers, cyclohexane, $\mathrm{n}$-hexane, and many other common organic solvents. Because of the more favourable physical and chemical characteristics of chloroform compared to other organic solvents, it was chosen and used for the rest of the studies.

\section{Effect of Time}

Equilibration was found to be established below 10 seconds, and further increase in time had no further effect on the extraction. The rate of attainment of extraction equilibrium has been known to be slow or very slow, for several extraction reagents, most notably, the $\beta$-diketones. This feature is contrasted by the present study.

\section{DISCUSSION}

We have studied spectrophotometrically the behaviour of $\mathrm{Cu}$ (II) with $\mathrm{HNP}_{\mathrm{Z}}$ and found that copper forms a bis-chelate with $\mathrm{HNP}_{\mathrm{Z}}$. Extraction is rapid as equilibrium is established within seconds. The degree of extraction was second-power dependent on 


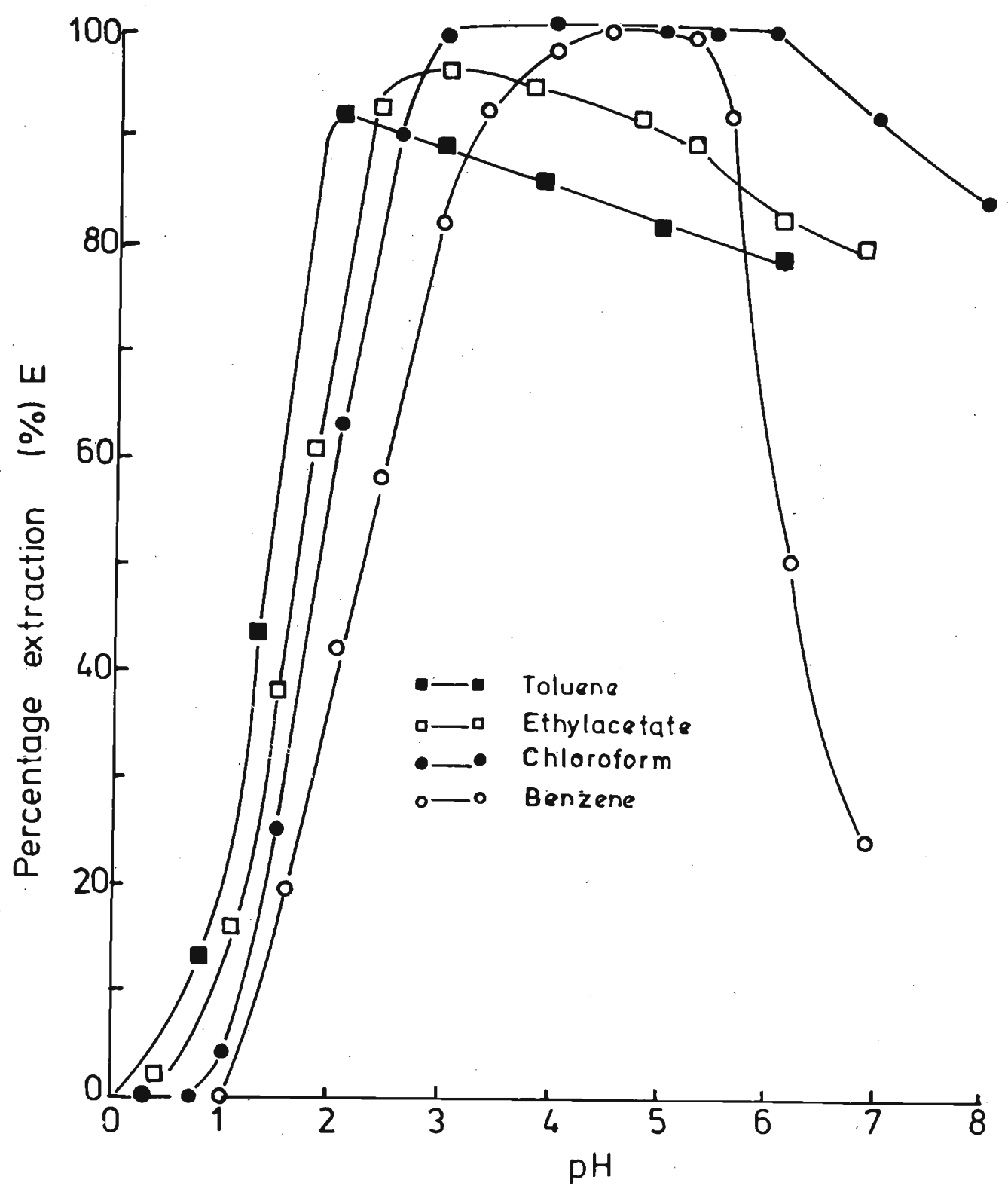

Figure 6: Efrect of solvents on Cu(II) extraction. ( $\bullet$ ) toluene, ( $\mathrm{Q}$ ) ethylacetate, ( $\bullet$ ) chloroform, (O) benzene; $[\mathrm{Cu}(\mathrm{II})]=2.0 \times \mathrm{I}^{-4} \mathrm{M},[\mathrm{IINP} \cdot \mathrm{Z}]=0.02 \mathrm{~N}$. 
$\mathrm{pH}$ and ligand concentration. As with most other acyl pyrazolones, $\mathrm{HNP}_{\mathrm{Z}}$ has several advantages over other $\beta$-diketones, such as benzoylacetone (BA, AA, TFA, TTA, etc., is being easily prepared and purified by recrystallization from alcohol) from readily available chemicals. It is characterized by good chemical stability and reasonable solubility in organic solvents. $\mathrm{HNP}_{\mathrm{Z}}$ is relatively cheap compared to fluorinated $\beta$. diketones (BMPP is about six times cheaper than TTA) ${ }^{5}$. Other conditions remaining the same, the more acidic character of the reagent should permit extraction of a considerable number of metals in more acidic solutions. $\mathrm{HNP}_{\mathrm{Z}}$ is recommended as a rapid extraction reagent for copper. Chloroform is also recommended, among others, as a suitable organic solvent.

\section{Acknowledgement}

The authors are grateful to Dr B.A. Uzoukwu for assistance in carrying out experiments.

\section{References}

1. Khopkar S.M. \& De A.K. (1960). Rapid extraction of iron (III) with 2-thenoyl trifluoroacetone. Analytica Chimica Acta 22:223-228.

2. Sekine T. \& Ilara N. (1971). Solvent extraction of $\mathrm{Fe}$ (III) \& $\mathrm{Cu}$ (II) with trifluoroacetylacetone. Bulletin of Chenical Society of Japan 44: 2942 - 2950.

3 Hasany S.M. \& Qureshi I.H. (1977). Extraction of group IB \& III - VA elements with 1-pheny1-3 methyl-4-trifluoroacetyl-pyrazolones-5. Journal of Radioanalytical Chemistry 40:29-39.

4. Nielsen, O.B, Poulsen, N.O.R, Sheline, R.K and Jensen, B.S (1959) Levels in Os ${ }^{190}$ populated in the decay of 11 day $\operatorname{Ir}^{190}$ Acta Chinica Scandinavia 147 59-b.

5 Rao G.N. \& Arora H.C. (1977). Solvent extraction of U(VI) with 4-Acyl-2, 4-Dihydro-5-methyl-2phenyl-3H-pyrazol-3-ones. Joumal of Inorganic \& Nuclear Chemistry 39: 2057 - 2060.

6. Okafor E.C.(1980). Structures of 1-phenyl-3-methyl-pyrazolone and its Derivatives (NMR, Mass and IR spectra). Zhumnal Naturforschtung 85b: 1019 - 1-23.

7 Forster D.S. (1978). Spectrophotometric Methods of Analysis. Metals Part I. p. 150. John Wiley, New York.

8 Mirza M.Y. (1978). Studies on extraction of $\mathrm{Cu}$ (II), Ga (III), In (III) and T1(III) with 1-phenyl-3-methyl-4-benzoylpyrazol-5-one. Talanta 25: 685-689.

9. Arora H.C. \& Roa G.N. (1973). Solvent extraction of $\mathrm{Cu}(\mathrm{II})$ \& $\mathrm{Ca}$ (II) using 4-Benzoyl-3-methyl-1-phenyl-5-pyrazolone. Indian Joumal of Chemistry 11: 488 -489 .

10. Zolotov Yu. A. (1970). Extraction of Chelate Compounds, pp. 119 Ann Arbor, London. 